\title{
Correction to: Parameters influencing complaints and joint function in patients with osteochondral lesions of the ankle-an investigation based on data from the German Cartilage Registry (KnorpelRegister DGOU)
}

\author{
Daniel Körner ${ }^{1}\left({ }^{10} \cdot\right.$ Boyko Gueorguiev $^{2} \cdot$ Philipp Niemeyer $^{3,4} \cdot$ Yannic Bangert $^{5} \cdot$ Wolfgang Zinser $^{6} \cdot$ Matthias Aurich $^{7}$. \\ Markus Walther $^{8} \cdot$ Christoph Becher $^{9} \cdot$ Atesch Ateschrang $^{1} \cdot$ Steffen Schröter ${ }^{1}$
}

Published online: 19 July 2018

(c) Springer-Verlag GmbH Germany, part of Springer Nature 2018

\section{Correction to: Arch Orthop Trauma Surg (2017) 137:367-373 https://doi.org/10.1007/s00402-017-2638-6}

The original version of this article contained an error. The values for the FAOS scores within the registry were wrong. The statistical recalculation with the corrected values thus revealed corrected $p$ values according to the FAOS scores. Thereby, among the total population patient age correlated significantly with the FAOS category Activities daily living $(p=0.04)$. Further substantial changes regarding the results of the study according to the corrected FAOS values and $p$ values were not found.

No significant association with the FAAM and FAOS scores was registered for the three lesion localizations (medial, central, lateral) among the 100 patients with a solitary treated talus lesion, i.e. there was no significant difference between the groups of patients with medial, central

The original article can be found online at https://doi.org/10.1007/ s00402-017-2638-6.

Daniel Körner

daniel.koerner@med.uni-tuebingen.de

1 Department of Traumatology and Reconstructive Surgery, BG Trauma Center Tübingen, Eberhard Karls University Tübingen, Schnarrrenbergstr. 95, 72076 Tübingen, Germany

2 AO Research Institute Davos, Davos, Switzerland

3 Department of Orthopedics and Trauma Surgery, Medical Center - University of Freiburg, Faculty of Medicine, University of Freiburg, Freiburg, Germany

4 OCM Klinik Munich, Munich, Germany

5 Department of Orthopedics and Trauma Surgery, Heidelberg University Hospital, Ruprecht Karls University Heidelberg, Heidelberg, Germany or lateral localization of the lesion with regard to the two scores $(p \geq 0.34)$.

Among both the entire population of 112 patients and the group of 100 patients with a solitary treated talus lesion, no significant correlation was found between defective area and FAAM as well as FAOS scores $(p \geq 0.11)$.

No significant association was identified between the lesion stage according to the ICRS classification and FAAM as well as FAOS scores among the entire population of 112 patients $(p \geq 0.10)$. A higher lesion stage according to the Berndt-Harty-Loomer classification was found to be significantly associated with higher values of the FAOS score categories Pain $(p=0.04)$ and Sports $(p<0.01)$.

No significant associations were identified between age, gender and BMI on one hand, and FAAM and FAOS scores on the other $(p \geq 0.14)$.

Below you find the corrected version of Table 2 with the corrected FAOS score values and $p$ values.

6 Department of Orthopedics and Trauma Surgery, St. Vinzenz Hospital Dinslaken, Dinslaken, Germany

7 Department of Orthopedics and Trauma Surgery, Sana Kliniken Leipziger Land, Borna, Germany

8 Department of Foot and Ankle Surgery, Schön Klinik Munich Harlaching, Munich, Germany

9 International Center for Hip, Knee and Foot Surgery, ATOS Klinik Heidelberg, Heidelberg, Germany 
Table 2 FAAM and FAOS

scores for patients with traumatic/posttraumatic lesions (group 1, $n=60$ ) and idiopathic lesions (group 2, $n=52$ )

together with $p$ values for their comparisons between the two groups

\begin{tabular}{|c|c|c|c|c|c|}
\hline & Category & Group & Median & Range & $p$ value \\
\hline \multirow[t]{10}{*}{ FAAM } & \multirow[t]{2}{*}{ Activities daily living } & 1 & 67.9 & $0-96$ & \multirow[t]{2}{*}{0.39} \\
\hline & & 2 & 61.1 & $0-100$ & \\
\hline & \multirow[t]{2}{*}{ Sports } & 1 & 25.0 & $0-72$ & \multirow[t]{2}{*}{0.62} \\
\hline & & 2 & 26.6 & $0-100$ & \\
\hline & \multirow[t]{2}{*}{ Function activities daily living } & 1 & 60.0 & $0-80$ & \multirow[t]{2}{*}{0.19} \\
\hline & & 2 & 49.0 & $0-85$ & \\
\hline & \multirow[t]{2}{*}{ Function sports } & 1 & 20.0 & $0-100$ & \multirow[t]{2}{*}{0.73} \\
\hline & & 2 & 20.0 & 0-209 & \\
\hline & \multirow[t]{2}{*}{ Function overall } & 1 & 2.00 & $2-4$ & \multirow[t]{2}{*}{0.31} \\
\hline & & 2 & 2.00 & $1-4$ & \\
\hline \multirow[t]{10}{*}{ FAOS } & \multirow[t]{2}{*}{ Symptoms } & 1 & 53.6 & $18-96$ & \multirow[t]{2}{*}{0.38} \\
\hline & & 2 & 64.3 & $21-100$ & \\
\hline & \multirow[t]{2}{*}{ Pain } & 1 & 69.4 & $31-100$ & \multirow[t]{2}{*}{0.56} \\
\hline & & 2 & 63.9 & $25-100$ & \\
\hline & \multirow[t]{2}{*}{ Activities daily living } & 1 & 78.7 & $21-97$ & \multirow[t]{2}{*}{0.82} \\
\hline & & 2 & 72.1 & 24-100 & \\
\hline & \multirow[t]{2}{*}{ Sports } & 1 & 35.0 & $0-75$ & \multirow[t]{2}{*}{0.71} \\
\hline & & 2 & 30.0 & $0-100$ & \\
\hline & \multirow[t]{2}{*}{ Life quality } & 1 & 37.5 & $12.5-62.5$ & \multirow[t]{2}{*}{0.03} \\
\hline & & 2 & 25.0 & $0-56.3$ & \\
\hline
\end{tabular}

